\title{
Factors associated with instrumental activities of daily living dependence in the elderly: a case-control study
}

\author{
Fatores associados à dependência para atividades instrumentais \\ da vida diária em idosos: estudo caso-controle
}

Ezequiel Vitorio Lini (https://orcid.org/0000-0003-4696-7068) ${ }^{1}$

Alisson Padilha de Lima (https://orcid.org/0000-0002-6062-446X) 1,2

Fabricio Bruno Cardoso (https://orcid.org/0000-0002-0279-6079) ${ }^{3}$

Marilene Rodrigues Portella (https://orcid.org/0000-0002-8455-7126) ${ }^{1}$

Marlene Doring (https://orcid.org/0000-0001-8551-8551) ${ }^{1}$
${ }^{1}$ Programa de PósGraduação em

Envelhecimento Humano, Universidade de Passo

Fundo (UPF). Passo Fundo RS Brasil.

${ }^{2}$ Escola de Educação Física, Faculdade IELUSC. R.

Mafra 84, Saguacu. 89221650 Joinville SC Brasil. professor.alissonpadilha@ gmail.com

${ }^{3}$ Escola de Educação Física, Faculdade de Ciências, Educação, Saúde, Pesquisa e Gestão (CENSUPEG). São Fidélis RJ Brasil.

\begin{abstract}
The main goal of the study was to determine the factors associated with dependence to perform instrumental activities of daily living in the elderly. A population-based case-control study was conducted, with 180 elderly people from Passo Fundo-RS, 2014. The cases were represented by 60 individuals aged $\geq 60$ years, dependents to perform instrumental activities of daily living residents of the urban area of the city. The controls were represented by 120 individuals, not dependents to perform instrumental activities of daily living, residents of the urban area of the city. Crude and multivariate analysis using Poisson regression were performed to test the association between the outcome and the independent variables, estimating the crude and adjusted odds ratios (OR) and calculating the 95\% confidence intervals respectively. All the variables with $p \leq$ 0.20 were included in the final model. Remained statistically significant after adjusted analysis: being aged 80 years or more $(\mathrm{OR}=1.76$; $C 195 \%$ : 1.01-3.08), having studied from 1 to 4 years (OR = 2.36; CI95\%: 1.35-4.14), being illiterate $(\mathrm{OR}=$ 2.98; CI95\%: 1.52-5.84), having Parkinson's disease (OR $=2.44$; CI95\%: 1.39-4.29) and the presence of cognitive impairment $(O R=1.88$; CI95\%: 1.30-2.72).

Key words Daily activities, Motor Activity, Population ageing
\end{abstract}

Resumo Esse estudo teve como objetivo determinar os fatores associados à dependência para atividades instrumentais da vida diária em idosos. Realizou-se um estudo caso-controle de base populacional, com 180 idosos de Passo Fundo-RS, 2014. Os casos foram representados por 60 indivíduos com idade $\geq 60$ anos, dependentes para as atividades instrumentais de vida diária residentes nos domicílios urbanos do município. Os controles foram representados por 120 idosos, não dependentes para atividades instrumentais de vida diária, residentes nos domicílios urbanos do município. Para testar a associação entre o desfecho $e$ as variáveis independentes, foram realizadas as análises brutas e multivariáveis mediante regressão de Poisson, estimando-se as razões de chance (OR) brutas e ajustadas e calculados os respectivos intervalos de confiança de 95\%. Entraram no modelo múltiplo todas as variáveis com $p \leq 0,20$. Permaneceram estatisticamente significativos após análise ajustada: estar na faixa etária de 80 anos ou mais (OR = 1,76; IC95\%: 1,01-3,08), ter estudado de 1 a 4 anos (OR = 2,36; IC95\%: 1,35$4,14)$, ser analfabeto $(O R=2,98$; IC95\%: 1,52 5,84), ter diagnóstico de Parkinson ( $O R=2,44$; IC95\%: 1,39-4,29) e apresentar comprometimento cognitivo (OR = 1,88; IC95\%: 1,30-2,72).

Palavras-chave Atividades cotidianas, Atividade Motora, Envelhecimento da população 


\section{Introduction}

Human ageing has been considered a worldwide occurrence, due to changes in the population pyramid and the increase in life expectancy ${ }^{1}$. As a consequence, health ageing has been associated with good functional capacity to perform basic and instrumental activities of daily living ${ }^{2}$.

Instrumental activities of daily living are considered to be more complex everyday skills needed to live independently, such as: using a telephone, using public transportation or driving, shopping, preparing meals, doing light housework, managing finances, making correct use of the medications, and may influence the biopsychosocial aspects of the elderly ${ }^{3}$. According to Ran et al. ${ }^{4}$ the low level of functional capacity in elderly to perform IADLs is associated with increased risk of cognitive impairment. The authors also list other factors that influence IADLs performance such as: low educational level and frequent consumption of medicines, negatively affecting the quality of life.

The social engagement in projects, works and activities involving elderly could present a positive association in IADLs, differing in the type of activities performed, the gender of the participants and their age ${ }^{5}$. The cognitive impairment associated with neurological diseases, such as Parkison's and Alzheimer's mostly, has been demonstrated in several researches since presenting strong association to IADLs dependence in elderly, due to its complex interaction in the neurological loss in specific areas of memory and motor control of the movements performed in daily taks ${ }^{4,6,7}$.

IADLs are more complex daily task and require more motor control to be performed ${ }^{8}$. Therefore, IADLs evaluation plays an important role in measuring the functional abilities in elderly and the impact of cognitive impairment on everyday activities?.

Given that, the objective of this study was to verify the factors associated with dependence to perform instrumental activities of daily living in elderly residing in the urban area of Passo Fundo-RS.

\section{Methods}

A population-based case-control study was performed with 180 elderly people in Passo Fundo-RS, In the period of 2014. The cases were represented by 60 individuals aged $\geq 60$ years, dependents to perform instrumental activities of daily living and residents of urban areas of the city. The controls were represented by 120 individuals people, not dependents to perform instrumental activities of daily living and residents of the urban areas of the city.

Passo Fundo is among the the most populated cities in Rio Grande do Sul state. It is located in the north of the state, 182 miles away from the capital, Porto Alegre. The estimated population is 187,298 thousand inhabitants; 22,222 of them are elderly aged sixty years or older ${ }^{10}$.

For the calculation of the sample size we drew four health units in each quadrant (as described below). Once each participating health unit was identified, a list of users 60 and older was requested. The sum of the elderly that each unit provided totaled 351 elderly. The prevalence of dependence for AIVDs found in the literature was $45 \%$. With these data the sample calculation was performed. Added $10 \%$ for possible refusals or losses, totaled 200 elderly needed for the study.

Regarding the case selection, the sample was from the urban territorial division demarcated by the Coordination of Basic Social Protection of Passo Fundo city ${ }^{11}$. The agency stipulated the quadrants of action for each Social Assistance Reference Center, divided into four major sectors: Sector I - Northeast region; Sector II - Northwest region; Sector III - Southeast region; Sector IV - Southwest region. In each of the sectors, a Basic Health Unit was chosen, in which the records (name and address) of all individuals aged $\geq 60$ years were searched. After that, 50 elderly people were randomly selected from each quadrant. All the elderly were initially interviewed regarding their IADLs performance. Sixty elderly individuals with some IADLs dependence were identified. There were left 140 elderly people without dependence (evaluated by the Lawton Scale), 120 of them were randomly selected to make up the control group, who were interviewed with the complete instrument. Therefore, we obtained the proportion of two controls for each case, totalizing 180 elderly.

The elderly who were hospitalized on the day of the interview (one in the institutions and one in the households) were excluded. Losses totaled $5.81 \%$ (24). Eligible individuals who refused to participate (6), did not sign the Informed Consent Form, were not found at home after three attempts by the interviewers on alternate days and times (3), and deaths occurred between the identification period of the elderly until data collection (15). 
Data collection was performed from April to August 2014. After the signing of the Free and Informed Consent Form, the collection was started. The data were collected in the residences by a trained team, formed by six scholarship holders and volunteers from the University of Passo Fundo Nursing School. A structured and pre-coded questionnaire was applied under continuous supervision of the responsible researcher. The elderly people were interviewed individually in separated places. If it was not possible for the elderly to respond, the information was obtained from the caregiver in the household.

The defined outcome was being dependent to perform at least one of the instrumental activities of daily living. The following variables were investigated to identify the possible factors associated to the dependence to perform instrumental activities of daily living: gender, age group, educational level, marital status, self-reported health status (self report), medication use, presence of dementia, sequelae of encephalic vascular accident (EVA), arthritis/arthrosis, hypertension, diabetes mellitus type II, Parkinson's disease, walking dependence and practice of physical activity (self report).

The Mini Mental State Examination (MMSE) was used to investigate the presence of cognitive deficit; the Bertolucci et al. ${ }^{12}$ study was used as a reference for cutoff points, with the following limits: 13 points for illiterate elderly, 18 points for those with low and average educational level (up to eight years of schooling) and 26 points for the elderly with high educational level (over eight years of schooling).

It was used to screen cognitive impairment the Pfeffer questionnaire - QPAF (a scale applied to the caregiver/responsible person when it is impossible for the elderly to respond, whether due to severe dementia, aphasia, deafness, etc.) proposed by Pfeffer et al..$^{13}$ and recommended by the Ministry of Health ${ }^{14}$ , it consists in verifying the presence of cognitive deficit considering the capacity of the individual to perform certain functions, for example: if he/ she is able to warm water for coffee or tea and put out the fire; if he/she is able to greet friends properly; pay attention and discuss about a television or radio program, among others. There are 11 questions with a maximum score of 33 points; the higher the score, the greater the dependence, which suggests the presence of dementia. The answers must conform to the following pattern: yes is capable (0); never did, but could do now (0); with difficulty, but does (1); never did and would have difficulty now (1); needs help (2); is not able (3). Scores greater than or equal to six suggest de- mentia, which can only be confirmed by a specific neuropsychological assessment. Accordingly, two instruments were used to determine the presence of symptoms that suggest cognitive impairment.

The Lawton's ${ }^{8}$ Scale was used to evaluate the IADLs performance, later recommended by the Ministry of Health ${ }^{14}$, it evaluates the functional capacity to perform some instrumental daily activities, such as using the telephone, using public transport, shopping, meal preparation, cleaning the house, doing handwork such as small repairs, washing and ironing clothes, taking the right medicine at the right time, and management of finances. The elderly with the maximum score 27 points - were considered independent. In case of total dependence to perform some of the tasks or needed help to complete them, the elderly was classified as dependent.

The other variables investigated were based on reports from the elderly or their responsible caregiver and later certified by medical records at the health unit, such as hypertension, diabetes, Parkinson's disease, EVA sequelae, use of medications, etc.

A descriptive and bivariate analysis of the data was run. In order to test the association between the outcome and the independent variables, the crude and multivariate analyzes were executed using Poisson regression, estimating crude and adjusted odds ratios (OR) and calculating the respective $95 \%$ confidence intervals. All variables with $\mathrm{p} \leq 0.20$ were included in the final model.

This article is part of the project Factors associated with the institutionalization of the elderly: a population-based case-control study, which was presented to the Research Ethics Committee of the University of Passo Fundo, RS, Brazil, and approved.

\section{Results}

The mean age was 71.4 years $( \pm 8.6), 60.6 \%$ female. Table 1 shows that higher age groups show greater IADLs dependence. Still, the lower the educational level the greater the number of dependents to perform IADLs. Finally, those who do not live with a partner suggest more dependence.

The Table 2 shows the factors associated with the clinical variables in IADLs dependence in the elderly. The following variables were significant: physical activity practice, walking dependence and presence of cognitive impairment.

Table 3 presents the crude and adjusted odds ratios in IADLs dependence. In the multiple 
Table 1. Characteristics of the elderly sample dependent to perform instrumental activities of daily living (cases) and non-dependent (controls). Passo Fundo, RS, Brazil, 2014 ( $\mathrm{N}=180)$.

\begin{tabular}{|c|c|c|c|c|c|c|c|}
\hline \multirow{2}{*}{ Variables } & \multicolumn{2}{|c|}{ Cases } & \multicolumn{2}{|c|}{ Controls } & \multicolumn{2}{|c|}{ Total } & \multirow{2}{*}{$\mathbf{p}^{*}$} \\
\hline & $\mathbf{n}$ & $\%$ & $\mathrm{n}$ & $\%$ & $\mathbf{n}$ & $\%$ & \\
\hline \multicolumn{8}{|l|}{ Gender } \\
\hline Female & 37 & 61.7 & 72 & 60.0 & 109 & 60.6 & $0.82 \mathrm{~S}$ \\
\hline Male & 23 & 38.3 & 48 & 40.0 & 71 & 39.4 & \\
\hline \multicolumn{8}{|l|}{ Age group } \\
\hline 60 to 69 years & 34 & 56.7 & 113 & 94.2 & 147 & 81.7 & $<0.001$ \\
\hline 70 to 79 years & 21 & 35.0 & 7 & 5.8 & 28 & 15.6 & \\
\hline$\geq 80$ years & 5 & 8.3 & 0 & 0.0 & 5 & 2.8 & \\
\hline \multicolumn{8}{|l|}{ Educational level } \\
\hline Illiterate & 15 & 25.0 & 6 & 5.0 & 21 & 11.7 & $<0.001$ \\
\hline From 1 to 4 years & 36 & 60.0 & 67 & 55.8 & 103 & 57.2 & \\
\hline 5 or more & 9 & 15.0 & 47 & 39.2 & 56 & 31.1 & \\
\hline \multicolumn{8}{|l|}{ Marital status } \\
\hline With a partner & 38 & 63.3 & 53 & 44.2 & 91 & 50.6 & 0.015 \\
\hline Without a partner & 22 & 36.7 & 67 & 55.8 & 89 & 49.4 & \\
\hline
\end{tabular}

model, it was verified that the age group over 80 years increases the odds of IADLs dependence. Those who did not study or studied less were more likely to be dependent than those who studied more. Elderly patients diagnosed with Parkinson's who presented cognitive impairment in the tests were more likely to be dependent than the elderly without Parkinson's disease and without cognitive impairment.

Therefore, remained statistically significant after adjusted analysis: being in the age group of 80 years or more, Parkinson's disease, having studied from 1 to 4 years, being illiterate, having and the presence of cognitive impairment.

\section{Discussion}

The results of the study are the associations between the outcome and the independent variables: age group of 80 years or more, having studied from 1 to 4 years, being illiterate, being diagnosed with Parkinson's disease and the presence of cognitive impairment. According to Tomioka et al. ${ }^{5}$ advanced age and gender can influence in the levels of IADLs in elderly, with scores identified in 22,845 elderly people from Naran province in Japan.

After analyzing 1.034 elderly people in Sao Paulo, the research of Alexandre et al. ${ }^{15}$ found that in the Brazilian population the age group over 80 years was determinant of IADLs disabil- ity as in the present study, showing higher incidence among women due to adverse clinical and social conditions. The older age group was also related to a greater risk of IADLs dependence in the study of Barbosa et al. ${ }^{16}$ carried out in Minas Gerais. According to the authors, to perform IADLs, it is necessary the full functioning of multiple physiological systems that in advanced age decline. Finally, they conclude that the degree of dependence in the elderly increases as they get older.

Low educational level and illiteracy rates are factors that influence the IADLs performance, one of the hypotheses may be the low level of understanding of the information needed to perform more complex tasks of the elderly daily living. A research developed by Nunes et al. ${ }^{17}$ in Bagé-RS with 1,593 individuals in the community identified the lower educational level, the greater the association with IADLs inability.

The study conducted by Ran et al. ${ }^{4}$ with age different from the present research, identified in 291 elderly people in the rural area of Yunan province in China, the researchers found a positive association with high educational level and higher quality of life, while IADLs dependence was associated with cognitive impairment and chronic diseases such as Alzheimer's and Parkinson's.

Parkinson's disease as the cognitive impairment caused by neurological disorders are influencing factors in IADLs dependence among 
Table 2. Distribution of the elderly dependent to perform instrumental activities of daily living (cases) and nondependent (controls), regarding clinical variables. Passo Fundo, RS, Brazil, 2014 ( $\mathrm{N}=180)$.

\begin{tabular}{|c|c|c|c|c|c|c|c|}
\hline \multirow{2}{*}{ Variables } & \multicolumn{2}{|c|}{ Cases } & \multicolumn{2}{|c|}{ Controls } & \multicolumn{2}{|c|}{ Total } & \multirow{2}{*}{$\mathbf{p}^{*}$} \\
\hline & $\mathbf{n}$ & $\%$ & $\mathbf{n}$ & $\%$ & $\mathbf{n}$ & $\%$ & \\
\hline \multicolumn{8}{|l|}{ Physical activitiy } \\
\hline Yes & 23 & 38.3 & 78 & 65.0 & 101 & 56.1 & 0.001 \\
\hline No & 37 & 61.7 & 42 & 35.0 & 79 & 43.9 & \\
\hline \multicolumn{8}{|l|}{ Walking dependence } \\
\hline Yes & 40 & 66.7 & 117 & 97.5 & 157 & 87.2 & $<0.001$ \\
\hline No & 20 & 33.3 & 3 & 2.5 & 123 & 12.8 & \\
\hline \multicolumn{8}{|l|}{ Parkinson's desease } \\
\hline Yes & 3 & 5.0 & 1 & 0.8 & 4 & 2.2 & 0.074 \\
\hline No & 57 & 95.0 & 119 & 99.2 & 176 & 97.8 & \\
\hline \multicolumn{8}{|l|}{ EVA motor sequelae } \\
\hline Yes & 3 & 5.0 & 2 & 1.7 & 5 & 2.8 & 0.200 \\
\hline No & 57 & 95.0 & 118 & 98.3 & 175 & 97.2 & \\
\hline \multicolumn{8}{|l|}{ Arterial hypertension } \\
\hline Yes & 46 & 76.7 & 82 & 68.3 & 128 & 71.1 & 0.245 \\
\hline No & 14 & 23.3 & 38 & 31.7 & 52 & 28.9 & \\
\hline \multicolumn{8}{|l|}{ Diabetes mellitus } \\
\hline Yes & 14 & 23.3 & 24 & 20.0 & 38 & 21.1 & 0.605 \\
\hline No & 46 & 76.7 & 96 & 80.0 & 142 & 78.9 & \\
\hline \multicolumn{8}{|l|}{ Arthritis/Arthrosis } \\
\hline Yes & 9 & 15.0 & 21 & 17.5 & 30 & 16.7 & 0.671 \\
\hline No & 51 & 85.0 & 99 & 82.5 & 150 & 83.3 & \\
\hline \multicolumn{8}{|l|}{ Medication $^{\star *}$} \\
\hline From 1 to 5 & 38 & 70.4 & 80 & 79.2 & 118 & 76.1 & 0.219 \\
\hline 6 or more & 16 & 29.6 & 21 & 20.8 & 37 & 23.9 & \\
\hline \multicolumn{8}{|l|}{ Cognitive impairment } \\
\hline Yes & 20 & 33.3 & 5 & 4.2 & 25 & 13.9 & $<0.001$ \\
\hline No & 40 & 66.7 & 115 & 95.8 & 155 & 86.1 & \\
\hline \multicolumn{8}{|l|}{ Health evaluation } \\
\hline Excellent/good & 26 & 43.3 & 69 & 57.5 & 95 & 52.8 & 0.073 \\
\hline Regular/poor/very poor & 34 & 56.7 & 51 & 42.5 & 85 & 47.2 & \\
\hline
\end{tabular}

${ }^{*}$ Value of $\mathrm{p}<0.050$ obtained by Pearson's chi-square test; ${ }^{* *}$ Number of medications used per day, some elderly did not provide information on the use of medications; EVA: Encephalic vascular accident.

elderly. The dependence occurs because specific areas of the cerebral cortex responsible for the motor control of movement execution are affected, causing the dependence and the low level of functional capacity to perform IADLs, as demonstrated by the results found in Ogama et al. ${ }^{6}$ after evaluating 347 women aged 65 to 85 years with and without cognitive impairment.

Ryu et al. ${ }^{7}$ also found similar results to this research, when identifying the association between mild cognitive impairment, depression and IADLs dependence among 66 elderly men with a mean age of 65 years residents of Daejeon, South Korea. 
Table 3. Crude and adjusted analysis of the factors associated with the dependence in the elderly to perform instrumental activities of daily living. Passo Fundo, RS, Brazil, 2014.

\begin{tabular}{|c|c|c|c|c|}
\hline Variables & $\mathrm{OR}^{\star}(\mathrm{IC} 95 \%)$ & $\mathbf{p}$ & OR (IC95\%) & $\mathbf{p}$ \\
\hline \multicolumn{5}{|l|}{ Gender } \\
\hline Male & 1.00 & & & \\
\hline Female & $0.95(0.62-1.46)$ & 0.830 & & \\
\hline \multicolumn{5}{|l|}{ Age group } \\
\hline 60-69 years & 1.00 & & 1.00 & \\
\hline 70-79 years & $3.24(2.25-4.67)$ & $<0.001$ & $1.49(0.93-2.40)$ & 0.099 \\
\hline$\geq 80$ years & $4.32(3.22-5.80)$ & $<0.001$ & $1.76(1.01-3.08)$ & 0.047 \\
\hline \multicolumn{5}{|l|}{ Educational level } \\
\hline 5 or more & 1.00 & & 1.00 & \\
\hline From 1 to 4 years & $2.17(1.31-4.18)$ & 0.020 & $2.36(1.35-4.14)$ & 0.003 \\
\hline Illiterate & $4.44(2.30-8.57)$ & $<0.001$ & $2.98(1.52-5.84)$ & 0.001 \\
\hline \multicolumn{5}{|l|}{ Marital status } \\
\hline With a partner & 1.00 & & 1.00 & \\
\hline Without a partner & $1.69(1.09-2.61)$ & 0.018 & & \\
\hline \multicolumn{5}{|l|}{ Physical activity practice } \\
\hline Yes & 1.00 & & 1.00 & \\
\hline No & $2.06(1.34-3.16)$ & 0.001 & $1.43(0.95-2.16)$ & 0.083 \\
\hline \multicolumn{5}{|l|}{ Walking dependence } \\
\hline Yes & 1.00 & & 1.00 & \\
\hline No & $3.41(2.50-4.66)$ & $<0.001$ & $1.33(0.91-1.94)$ & 0.136 \\
\hline \multicolumn{5}{|l|}{ Parkinson's desease } \\
\hline No & 1.00 & & 1.00 & \\
\hline Yes & $2.32(1.26-4.24)$ & 0.006 & $2.44(1.39-4.29)$ & 0.002 \\
\hline \multicolumn{5}{|l|}{ EVA motor sequelae } \\
\hline No & 1.00 & & & \\
\hline Yes & $1.84(0.87-3.88)$ & 0.109 & & \\
\hline \multicolumn{5}{|l|}{ Arterial hypertension } \\
\hline No & 1.00 & & & \\
\hline Yes & $1.33(0.81-2.21)$ & 0.261 & & \\
\hline \multicolumn{5}{|l|}{ Diabetes mellitus } \\
\hline No & 1.00 & & & \\
\hline Yes & $1.14(0.70-1.84)$ & 0.599 & & \\
\hline \multicolumn{5}{|l|}{ Arthritis/arthrosis } \\
\hline No & 1.00 & & & \\
\hline Yes & $0.88(0.49-1.59)$ & 0.678 & & \\
\hline \multicolumn{5}{|l|}{ Medication $^{\star *}$} \\
\hline From 1 to 5 & 1.00 & & & \\
\hline 6 or more & $1.34(0.85-2.11)$ & 0.202 & & \\
\hline \multicolumn{5}{|l|}{ Cognitive impairment } \\
\hline No & 1.00 & & 1.00 & \\
\hline Yes & $3.10(2.23-4.32)$ & $<0.001$ & $1.88(1.30-2.72)$ & 0.001 \\
\hline \multicolumn{5}{|l|}{ Health evaluation } \\
\hline Excellent/good & 1.00 & & 1.00 & \\
\hline Regular/poor/very poor & $1.46(0.96-2.22)$ & 0.075 & $1.26(0.87-1.83)$ & 0.225 \\
\hline
\end{tabular}


of spatial perception, memory and attention difficulties which makes social and intellectual tasks more difficult ${ }^{17}$.

According to a cohort study conducted in China by researchers Li et al. ${ }^{19}$, chronic diseases such as hypertension, diabetes mellitus and cerebrovascular diseases may compromise IADLs at more advanced ages as identified in the present study. Thus, patients suffering from critical illness who are hospitalized in an intensive care unit and pathologies such as Parkinson's and different types of cancer are potential factors of disability for the IADLs in adults and the elderly ${ }^{20-22}$.

It is worth mentioning that the study presented some limitations that do not permit a generalization of these results, as a local study, in which is identified the real situation exclusive to a city in question. The positive points that reassure the data stand out: the case control design, considered a good design for a research of this nature. The fact that it is a population-based research is another positive point, since this is not considered a common practice in scientific research with elderly, cooperating with the scientific and social communities in the region.

This research demonstrated that the predisposing factors related to the dependence to perform instrumental activities of daily living are advanced age ( 80 years or more), having studied from 1 to 4 years, being illiterate, having Parkinson's disease and the presence of cognitive impairment.
Actions aimed at maintaining physical conditions and active participation in society should be encouraged to keep the maximum safe IADLs performance. Strengthening health prevention work in the Family Health Strategies and encouraging greater participation in elderly groups, for example, may positively influence the maintenance of the capacity to perform instrumental activities of daily living.

The choice of a case-control design in the elderly allows us to investigate the etiology of diseases and health-related conditions. They depart from the effect for further investigation of the cause and present advantages such as: shorter time to develop the study, lower cost of research, absence of risks for the participants and possibility to investigate different etiological hypotheses simultaneously. As for biases, in this type of study errors of selection and memory may occur (cases and controls may have a different capacity to remember the history of exposure). Therefore, it is admitted that there may have been a chance of underreporting of chronic diseases during instrument filling through the reports of the elderly, however, all the interviewees attended health facilities, which may have alleviated this problem.

It is recommended that other studies are carried out with greater sampling magnitude and different designs so that IADLs can be monitored and prevention programs to maintain functional independence during the ageing process promoted providing a better quality of life for the elderly population.

\section{Collaborations}

EV Lini participated in all stages of this work since the conception of the study. AP Lima participated in the analysis of the data and the final writing of the article. MR Portella participated in all stages of this work and supervised the final writing. M Doring supervised all stages of this work and assisted in the writing of the article. FB Cardoso participated in the writing and correction of the final version of the manuscript. 


\section{References}

1. Camarano AM. Brazilian population ageing: differences in well-being by rural and urban areas. Brasília: IPEA; 2015.

2. World Health Organization (WHO). World report on ageing and health. Geneva: WHO Library; 2015.

3. Brown J, Kurichi JE, Xie D, Pan Q, Stineman MG. Instrumental activities of daily living staging as a possible clinical tool for falls risk assessment in physical medicine and rehabilition. PM R 2014; 6(4):316-323.

4. Ran L, Jiang X, Li B, Kong H, Du M, Wang X, Yu H, Liu Q. Association among activities of daily living, instrumental activities of daily living and health-related quality of life in elderly Yi ethnic minority. BMC Geriatr 2017; 17(1):74.

5. Tomioka K, Kurumatani N, Hosoi H. Age and gender differences in the association between social participation and instrumentalactivities of daily living among community-dwelling elderly. BMC Geriatr 2017; 17(1):99.

6. Ogama N, Sakurai T, Nakai T, Niida S, Saji N, Toba K. Impact of frontal white matter hyperintensity on instrumental activities of daily living in elderly women with Alzheimer disease and amnestic mild cognitive impairment. PLoS One 2017; 12(3):e0172484.

7. Ryu SY, Lee SB, Kim TW, Lee TJ. Subjective memory complaints, depressive symptoms and instrumental activities of daily living in mild cognitive impairment. Int Psychogeriatr 2016; 28(3):487-494.

8. Lawton MP, Brody EM. Assessment of older people: self-maintaining and instrumental activities of daily living. Gerontologist 1969; 9(3):179-186.

9. Gold DA. An examination of instrumental activities of daily living assessment in older adults and mild cognitive impairment. J Clin Exp Neuropsychol 2012; 34(1):11-34.

10. Instituto Brasileiro de Geografia e Estatística (IBGE). Censo Demográfico 2010: resultados gerais da amostra. Rio de Janeiro: IBGE; 2012.

11. Prefeitura Municipal de Passo Fundo. Secretaria de Cidadania e Assistência Social [Internet]. 2014 [acessado 2017 Jun 26]. Disponível em: http://www.pmpf. rs.gov.br/secao.php? $=1300 \& a=2 \& p m=49$

12. Bertolucci PHF, Brucki SMD, Campacci SR, Juliano Y. O mini-exame do estado mental em uma população geral impacto da escolaridade. Arq Neuropsiq 1994; 52(1):1-7.

13. Pfeffer RI, Kurosaki TT, Harrah CH Jr, Chance JM, Filos S. Measurement of functional activities in older adults in the community. J Geront 1982; 37(3):323329.

14. Brasil. Ministério da Saúde (MS). Envelhecimento e saúde da pessoa idosa. Brasília: MS; 2006.

15. Alexandre TS, Corona LP, Nunes DP, Santos JLF, Oliveira YAD, Lebrão ML. Incapacidade em atividades instrumentais de vida diária em idosos: diferenças de gênero. Rev Saúde Pública 2014; 48(3):379-389.

16. Barbosa BR, Almeida JM, Barbosa MR, Rossi-Barbosa LAR. Avaliação da capacidade funcional dos idosos e fatores associados à incapacidade. Cien Saude Colet 2014; 19(8):3317-3325.
17. Nunes JD, Saes MO, Nunes BP, Siqueira FCV, Soares DC, Fassa MEG, Thumé E, Facchini LA. Indicadores de incapacidade funcional e fatores associados em idosos: estudo de base populacional em Bagé, Rio Grande do Sul. Epidemiol Serv Saúde 2017; 26(2):295304.

18. Ryu SY, Lee SB, Kim TW, Lee TJ. Memory complaints in subjective cognitive impairment, amnestic mild cognitive impairment and mild Alzheimer's disease. Acta Neurol Belg 2016; 116(4):535-541.

19. Li ZY, Wu JL, Li JJ, Pei JL. A cohort study on the influence of the chronic diseases on activities of daily living of the elderly aged 65 years and over in China. Zhonghua Liu Xing Bing Xue Za Zhi 2019; 40(1):33-40.

20. Hopkins RO, Suchyta MR, Kamdar BB, Darowski E, Jackson JC, Needham DM. Instrumental Activities of Daily Living after Critical Illness: A Systematic Review. Ann Am Thorac Soc 2017; 14(8):1332-1343.

21. Perry SIB, Nelissen PM, Siemonsma P, Lucas C. The effect of functional-task training on activities of daily living for people with Parkinson`s disease, a systematic review with meta-analysis. Complement Ther Med 2019; 42:312-321.

22. Neo J, Fettes L, Gao W, Higginson IJ, Maddocks M. Disability in activities of daily living among adults with cancer: A systematic review and meta-analysis. Cancer Treat Rev 2017; 61:94-106.
Article submitted 30/10/2018

Approved 20/03/2019

Final version submitted 22/03/2019 